\title{
Editorial, Special Issue Inaugural Conference of the IS4CE
}

\author{
Ken Webster ${ }^{1}$ - Alexandros Stefanakis ${ }^{2}$ \\ Published online: 10 August 2021 \\ (C) The Author(s), under exclusive licence to Springer Nature Switzerland AG 2021
}

The International Society for the Circular Economy (IS4CE) is as an independent international academic society run by and for its members, established around a core development group in 2019/20. IS4CE is a transdisciplinary exercise centered on, but not exclusive to, the potential of the digital revolution to improve our understanding of systems aimed at "circularity" and its fundamental effects on the relationship between people, resources, business, and enterprise.

IS4CE organized its inaugural conference during 6-7 July 2020, hosted digitally by Linköping University, Sweden. Selected papers presented at the conference were invited and submitted to the Circular Economy and Sustainability journal to form this special issue.

The scarcity of natural resources is a crucial factor that impacts the effectiveness and continuity of economy and production. The overproduction to meet the demands of the growing global population requires huge amounts of natural resources. Attempts such as to reduce or eliminate the consumption of natural resources, to slow the use of materials, and to close the cycle of waste materials are today viewed under the concept of circular economy. However, circular economy does not stop there. Actually, the extent of its content and its application range is always expanding as we realized that circular thinking should be an inherent part of any economic and even social activity. This is also indicated by the papers of this special issue that examine circular economy aspects in different fields, industries, and disciplines. As IS4CE and this new scientific journal arguably aim at promoting, we need a better definition and deeper investigation of circular economy potential to meet social and environmental goals.

The expansion of interest in the notion of a circular economy in the research community took off after 2012. Outside of this community, the initial reframing of this notion as a heuristic was intended to rest on four key propositions or proposals. Firstly, as "an economic opportunity driven by innovation" (Stahel), it appeals to business, reinforced by the digital revolution which loosened up the opportunity to rework business models. The second proposal was around decoupling materials and resources generally from economic growth, so it appealed to mainstream policy actors. Thirdly, it suggested some gains in employment as production and

Alexandros Stefanakis astefanakis@enveng.tuc.gr

1 Centre for Circular Economy, University of Exeter, Exeter, UK

2 School of Chemical and Environmental Engineering, Technical University of Crete, Chania, Greece 
particularly service and customer care, repair, refurbishment, and recovery come closer to home. And if built on renewables and energy efficiency, it is especially coherent. Lastly, it has a backgrounded affiliation to feedback rich systemic approaches increasingly pervasive in science. Especially cogent is the logic of capital rebuilding and restoration as a potential outcome of circularity. Things can get better, not just a slowed degradation. It thus has a present-day-to-future orientation rather than a present-to-past so pervasive in the industrial era which was end-of-the-pipe: about dealing with waste and recycling. In short, contemporary circular economy embraces of progress and innovation, entrepreneurship and great design, of apps and on demand services. It highlighted participants as eco-aware, post-modern, diverse, and digitally savvy, a deeply cool mesh of communities, no sackcloth and ashes, no guilt, just better products and services done right.

Working from the other end, from outside the economy were those who saw a last watering hole for sustainability and a co-optable ally in challenging the economy to deal with its multiple ecological and social crises or saw signs of a more socially-orientated distributed economy made up of small or informal business leveraging open source, socially produced cascaded materials in redesigned cities and communities. It also felt like one brand of toolkit for the SDGs, the SDGs being a list of good things rather than having much in the way of practical tools attached.

Into this mix comes the research community interested in a myriad of things, as indeed this is where its strength lies. And the spectrum of this is easily gauged in this special issue: physics, psychology; social development; product as service; extended product life; change management; and environmental metrics.

This is described as a strength particularly as after about 10 years of the general increase in enthusiasm for circular economy and sustainability it is time to get serious and sort out what works and what does not, what's profound and what is junk food for the mind. There is so much work to be done of course, it's every researcher's dream, but what the diversity of research here reveals is also a potential pitfall. Is this a case of reworking existing or putative research to add the label du jour, in which case it becomes a nice fruit salad? Lots of tasty bits but the word "fruit" is the only connective idea. Or because it is well known that metaphor underlies all abstract thought (Lakoff) it might be a lens on how we see the work, it does then have sufficient coherence, built on its "complex systems" orientation on its "insights from living system" metaphor base, which stresses context and mutual dependency and the creation of effective, all scale, accessible, genuinely regenerative, and restorative system.

That is the test for research work in circular economy and sustainability: remembering that there is a huge role for narrative when it comes to change (Harari) and what we agree on needs to be a foundation for diversity, for creativity, but also to adopt ideas from designer Christopher Alexander that as systems thinkers we are looking for patterns and creating a pattern language, as from that language properly understood comes something durable and with that we can recognize and enhance the quality of our living. 